\title{
CARACTERIZAÇÃO DE FRUTOS E POLIEMBRIONIA EM SEMENTES DE 'FLYING DRAGON' E DE HÍBRIDOS DE PORTA-ENXERTO DE CITROS ${ }^{1}$
}

\author{
RODRIGO AMATO MOREIRA², JOSÉ DARLAN RAMOS ${ }^{3}$, \\ MARIA DO CÉU MONTEIRO DA CRUZ ${ }^{4}$
}

RESUMO - A diversificação de porta-enxertos é uma realidade no momento atual da citricultura brasileira, devido aos inúmeros problemas fitossanitários que vêm sendo recorrentes. Neste contexto, algumas alternativas já são implementadas, como a utilização de alguns híbridos produzidos a partir do melhoramento convencional e por variedades já consagradas na citricultura. O presente trabalho foi realizado com o objetivo de caracterizar os frutos e avaliar a germinação e a poliembrionia das sementes de híbridos e alguns portaenxertos convencionais. Para caracterização, foram colhidas, ao acaso, 12 amostras (frutos) de cada portaenxerto. Na avaliação do percentual de germinação, índice de velocidade de germinação e poliembrionia, foi utilizado o esquema fatorial 5 (porta-enxertos: híbridos UFLAD-2, UFLAD-3 e UFLAD-4, citrumeleiro 'Swingle' e o Poncirus trifoliata var. monstrosa 'Flying Dragon') x 2 (com e sem a remoção do tegumento da semente), sendo utilizadas quatro repetições. De acordo com os resultados obtidos, concluiu-se que: O tamanho do fruto não influenciou no rendimento de sementes. A remoção do tegumento acelerou o tempo de germinação das sementes em todos os porta-enxertos e proporcionou maior percentual de germinação. A poliembrionia não afetou o processo de germinação das sementes. Os porta-enxertos UFLAD-2, UFLAD-3, UFLAD-4 e citrumeleiro 'Swingle' apresentam potencial para serem utilizados como porta-enxertos na propagação de algumas variedades cítricas.

Termos para indexação: Propagação, citricultura, mudas.

\section{FRUIT CHARACTERIZATION AND SEED POLYEMBRYONY OF 'FLYING DRAGON'AND OF CITRUS ROOTSTOCKS HYBRIDS}

\begin{abstract}
The diversification of the rootstocks is a reality at the moment of the Brazilian citriculture, due to many problems that have been recurring. In this context some alternatives are already a reality as the use of some hybrids produced through conventional breeding and varieties already used in citrus. This work was carried out aiming to characterize the fruit and evaluate the germination and the polyembryony of the seed. For the characterization, 12 samples of each rootstock were randomly collected. In the evaluation of the germination percentage, germination speed index and polyembryony, it was used a factorial scheme 5 (the rootstocks: hybrid UFLAD-2, UFLAD-3 and UFLAD-4, citrumeleiro 'Swingle' and Poncirus trifoliata var. monstrosa 'Flying Dragon') x 2 (with and without removing the seedcoat), with four replications. According to the results it is concluded that the fruit size did not influence in the seed yield. The removal of the seedcoat accelerated the time of seed germination in all the rootstocks and provided a higher germination percentage. The polyembryony did not affect the process of seed germination. The rootstocks UFLAD-2, UFLAD-3, UFLAD-4 and citrumeleiro 'Swingle' have potential to be used in the production of rootstocks. Index terms: Propagation, citriculture, seedlings.
\end{abstract}

\footnotetext{
${ }^{1}$ (Trabalho 115-09). Recebido em: 13-05-2009. Aceito para publicação em: 04-12-2009.

${ }^{2}$ Mestrando em Fitotecnia, UFLA. Cx. Postal 3037, Lavras-MG, CEP 37200-000. Bolsista do CNPq, amatomoreira@yahoo.com.br ${ }^{3}$ Dr., Professor do Departamento de Agricultura, UFLA, Cx. Postal 3037, Lavras-MG, CEP 37200-000, darlan@ufla.br

${ }^{4}$ Pós-Doutoranda em Fitotecnia, UFLA. Cx. Postal 3037, Lavras-MG, CEP 37200-000. Bolsista do CNPq, m_mariceu@yahoo.com.br
} 


\section{INTRODUÇÃO}

Com o surgimento de inúmeros problemas fitossanitários na citricultura brasileira, a diversificação de porta-enxertos torna-se uma das principais alternativas. O principal porta-enxerto utilizado nos últimos anos tem-se mostrado suscetível a alguns problemas fitossanitários, principalmente com relação à incidência da 'gomose', 'declínio' e mais recentemente à 'morte súbita do citros'

Dentre as variedades de porta-enxertos existentes, destacam-se aquelas provenientes de Poncirus trifoliata, porta-enxerto que confere as características de baixo porte, resistência a doenças e produção de frutas de alta qualidade às copas de diversas variedades cítricas (PASSOS et al., 2006) e principalmente por conferir tolerância ao frio (OLIVEIRA et al., 2001). E atualmente por eles terem-se mostrado tolerantes à 'morte súbita dos citros'.

Alternativas já são realidade em algumas instituições de pesquisa, a exemplo dos híbridos produzidos na UFLA (RAMOS, 1997), denomidados de UFLAD-2, UFLAD-3 e UFLAD-4. Sendo híbridos de Poncirus trifoliata (L.) Raf., esses porta-enxertos apresentam o tegumento das sementes mais coriáceo que os demais porta-enxertos de citros, propiciando a podridão das sementes durante a germinação (ROUSE,1997). Nessas sementes, o tegumento pode ser o fator principal limitante à germinação, pois o número de dias decorridos para ocorrer a germinação resulta em desuniformidade entre as plântulas, retardando a fase de formação dos porta-enxertos (SOUSA et al., 2002).

Na busca de alternativas para a diversificação no uso de porta-enxertos, o interesse é por variedades que proporcionem bom rendimento de sementes e que estas apresentem germinação satisfatória e vigor ao porta-enxerto.

Em citros, o vigor do porta-enxerto tem sido associado ao número de embriões por sementes, de modo que o menor número de embriões por sementes favorece o aumento no tamanho do embrião e a germinação do embrião zigótico (SOARES et al., 2000), fato comum em muitas espécies de citros, chamado de poliembrionia.

Para a formação dos porta-enxertos, a presença de vários embriões numa mesma semente pode dificultar a sobrevivência dos embriões zigóticos, devido à competição dos embriões nucelares (SOARES FILHO et al., 2002), contribui para manter as características genéticas do porta-enxerto, proporcionando a obtenção de plantas semelhantes à planta-matriz.

De acordo com Passos et al. (2006), quanto mais elevada a taxa de poliembrionia, maiores são as chances de o porta-enxerto, quando propagado por semente, germinar plântulas de origem nucelar, semelhantes à cultivar-mãe. Uma vez que a semente possui somente um embrião zigótico e os demais embriões presentes são oriundos da nucela, que é um tecido materno, portanto com a mesma constituição genética da cultivar-mãe.

Outro aspecto relacionado ao número de embriões por semente é o baixo vigor apresentado por alguns porta-enxertos, em decorrência da alta taxa de poliembrionia das sementes, que, por competição entre os vários embriões nucelares ou pela superação e germinação do embrião zigótico, geralmente reduz o vigor das plântulas germinadas a partir dessas sementes (RAMOS et al., 2006).

Assim, o presente trabalho foi desenvolvido com o objetivo de caracterizar frutos e sementes de híbridos e variedades de porta-enxertos de citros para avaliar a poliembrionia e a germinação de sementes com e sem a remoção do tegumento.

\section{MATERIAL E MÉTODOS}

O trabalho foi conduzido durante o período de março a maio de 2008, no Setor de Fruticultura do Departamento de Agricultura na Universidade Federal de Lavras (UFLA), Lavras - MG.

Foram coletados frutos maduros dos híbridos UFLAD-2, UFLAD-3 e UFLAD-4, oriundos do cruzamento intergenérico do limoeiro 'Cravo' (parental feminino) com Poncirus trifoliata (L) Raf. (parental masculino), do citrumeleiro 'Swingle' (Citrus paradisi Macf. $\mathrm{x}$ Poncirus trifoliata) e do 'Flying Dragon' (Poncirus trifoliata var. monstrosa) da coleção de variedades de porta-enxertos implantada no pomar do Setor de Fruticultura da UFLA.

Para a caracterização dos frutos, foram colhidas ao acaso quatro amostras de 12 frutos para cada porta-enxerto. Nesses frutos, avaliaram-se as seguintes variáveis: diâmetro transversal (DT), diâmetro longitudinal (DL) e massa dos frutos (MF), número total de sementes por fruto (NSF) e número de sementes viáveis por fruto (NSV).

Após a extração, as sementes foram colocadas em contato com cal e lavadas em água corrente para a retirada da mucilagem. Em seguida, foram imersas em solução de hipoclorito de sódio a $20 \%$, por 3 minutos, e em álcool etílico a 70\%, por 1 minuto. Essas foram colocadas para secar à sombra, permanecendo por um período de três dias. Após a secagem, foi feita a seleção das sementes, eliminando-se as inviáveis (chochas), para a determinação do número de sementes viáveis por fruto. Antes da semeadura, as 
sementes receberam tratamento térmico, realizado por imersão em água a $52^{\circ} \mathrm{C}$, por 10 minutos.

Para a avaliação do percentual de germinação, índice de velocidade de germinação e poliembrionia, foi utilizado o esquema fatorial $5 \times 2$, no delineamento inteiramente casualizado, sendo os fatores cinco porta-enxertos cítricos (os híbridos UFLAD-2, UFLAD-3, UFLAD-4, citrumeleiro 'Swingle', e o Poncirus trifoliata var. monstrosa 'Flying Dragon') e dois tratamentos do tegumento da semente (com e sem remoção do tegumento), com quatro repetições e vinte sementes por parcela.

A semeadura foi realizada em tubetes, distribuindo-se uma semente por tubete preenchidos com o substrato Plantmax ${ }^{\circledR}$. As bandejas com os tubetes foram colocadas em bancadas a um metro da superfície do solo, deixadas sob telado coberto por sombrite com $50 \%$ de luminosidade.

As irrigações foram realizadas diariamente, suficientes para manter a umidade do substrato próximo à capacidade de campo, conforme estimado em ensaios anteriores mediante a pesagem das perdas diárias.

Aos 12 dias após a semeadura, observou-se o início da germinação, adotando-se como critério para a germinação a protrusão de $1 \mathrm{~mm}$ de radícula. Foram realizadas contagens a cada dois dias, do $12^{\circ}$ a $60^{\circ}$ dia, para avaliar a porcentagem final de germinação, o índice de velocidade de germinação (IVG), o número de embriões germinamos por semente e a porcentagem de poliembrionia em sementes germinadas. Para o cálculo do IVG, foi utilizada a fórmula sugerida por Maguire (1962).

Os dados obtidos foram submetidos à análise de variância, correlação de Pearson, e as médias, comparadas pelo teste de Scott-Knott, a $5 \%$ de probabilidade de erro.

\section{RESULTADOS E DISCUSSÃO}

Foi observada interação entre os portaenxertos e o tratamento do tegumento da semente para as variáveis porcentagem de germinação, IVG, número de embriões por semente e percentual de poliembrionia.

A caracterização realizada nos frutos dos porta-enxertos indicou que o citrumeleiro 'Swingle' apresenta frutos com maiores diâmetros, massa e número total de sementes por fruto (Tabela 1). Entretanto, para o número de sementes viáveis, o 'Flying Dragon' destacou-se com rendimento de 36 sementes por fruto. Apesar do menor número de sementes viáveis observado nos fruto dos porta-enxertos híbridos, a quantidade de 26 no citrumeleiro 'Swingle' 14 no
UFLAD-2 e 13 UFLAD-4 foi superior à quantidade de sementes avaliadas em frutos de limoeiro 'Cravo', que apresentam em média de 7,8 (SOARES-FILHO, 2002) a 12 sementes por fruto (RAMOS et al., 1997).

O maior número de sementes observado no citrumeleiro 'Swingle' ocorreu em função da ocorrência de grande quantidade de inviáveis. Resultados semelhantes foram observados por Ramos et al. (2006), enquanto os demais porta-enxertos avaliados apresentaram maiores quantidades de sementes selecionadas como viáveis.

Correlacionando o tamanho do fruto, diâmetro e massa, com o número de sementes, observaramse correlações negativas entre o diâmetro e o número de sementes viáveis $(-0,9366)$ e entre a massa e o número de sementes viáveis $(-0,9311)$, para o híbrido UFLAD-2 e citrumelo 'Swingle' (Tabela 2). Para os demais porta-enxertos, não se verificou correlação entre essas características avaliadas. A correlação negativa observada no híbrido UFLAD-2 e 'Swingle' pode ser atribuída ao alto número de sementes malformadas avaliada nos frutos destes porta-enxertos.

De maneira geral, os resultados demonstram que não há correlação direta do tamanho do fruto com o rendimento de sementes, pois o 'Flying Dragon' que apresentou o maior número de sementes viáveis não demonstrou correlação com o diâmetro ou massa avaliada nos seus frutos.

Nas sementes em que o tegumento foi removido, observou-se maior percentual de germinação, em todos os porta-enxetos estudados (Tabela 3). Esse resultado evidencia que o tegumento é o principal fator limitante para a germinação das sementes desses porta-enxertos, que possivelmente apresentam baixa germinação em decorrência da escassa absorção de água e/ou a perdas de sementes causada pelo longo período, se elas permanecem no substrato Plant$\max { }^{\circledR}$. (ROUSE, 1997).

Nas sementes dos porta-enxertos em que não foi realizada a remoção do tegumento, o percentual de germinação foi baixo, obtendo-se germinação máxima de $25 \%$ no híbrido UFLAD-2, 21,25\% no híbrido UFLAD-3, 18,75\% no híbrido UFLAD-4 e no citrumeleiro 'Swingle', os quais diferiram apenas do 'Flying Dragon', que apresentou o menor percentual de germinação, de $6,25 \%$ (Tabela 3 ). No entanto, com a retirada do tegumento, as sementes dos híbridos UFLAD-2, UFLAD-3 e UFLAD-4 apresentaram os maiores percentuais de germinação, quando comparados ao citrumeleiro 'Swingle', que apresentou $81,25 \%$, e o 'Flying Dragon', com $48,75 \%$, apresentou o menor percentual de germinação.

O aumento no percentual de germinação 
também foi constatado por Oliveira e Scivittaro (2007) em sementes de Trifoliata com a remoção do tegumento. Os maiores percentuais de germinação observados nas sementes dos híbridos UFLAD-2, UFLAD-3 e UFLAD-4 são superiores aos observados por Oliveira et al. (2007) em sementes de limoeiro 'Cravo' com a remoção do tegumento.

Em relação ao IVG, os resultados foram semelhantes aos observados para o percentual de germinação, e as sementes que tiveram o tegumento removido, apresentaram também os maiores índices para todos os porta-enxertos avaliados (Tabela 3). Esse resultado indica que esses porta-enxertos, quando submetidos a tratamentos que facilitem a ruptura do tegumento das sementes, apresentam germinação uniforme, além de não prolongar o tempo para a formação do porta-enxerto, verificando-se maiores percentuais de germinação aos 60 dias após o plantio.

A velocidade de emergência nos portaenxertos híbridos, quando feita a remoção do tegumento das sementes, é semelhante aos resultados observados em limoeiro 'Cravo' por Schäfer et al. (2005), que atingiu níveis de 95\% aos 114 dias após o plantio.

Nas sementes que não tiveram o tegumento removido, o citrumeleiro 'Swingle' foi o que apresentou maior vigor, quando comparado aos demais porta-enxertos (Tabela 3). Por outro lado, no IVG avaliado nas sementes, em que foi realizada a remoção do tegumento, os híbridos UFLAD-2, UFLAD-3 e UFLAD-4 apresentaram melhores resultados, seguidos do Citrumeleiro 'Swingle' e do 'Flying Dragon' com o menor vigor.

$\mathrm{O}$ vigor observado nas sementes dos portaenxertos híbridos, quando foram submetidas ao tratamento de remoção do tegumento, é superior ao de sementes de limoeiro 'Cravo' (SOUSA et al., 2002), comprovando o baixo vigor apresentado na germinação de sementes desses porta-enxertos, que é limitado pelo tegumento de suas sementes.

Quanto ao número de embriões germinados por semente, os híbridos UFLAD-2, UFLAD-3 e UFLAD-4 apresentaram os melhores resultados, em ambos os tratamentos, com e sem tegumento. Nestes porta-enxertos, o número de embriões por semente foi maior nas sementes em que foi feita a remoção do tegumento com 2,$5 ; 2,5$ e 2,7 , respectivamente (Tabela 3).

Para a taxa de poliembrionia, não houve interação dos porta-enxertos com o tratamento do tegumento. Os híbridos UFLAD-2, UFLAD-3 e UFLAD-4 apresentaram os maiores percentuais, com 81,3; 81, 0 e 79,1, respectivamente, observando- se nos porta-enxertos citrumeleiro 'Swingle' e 'Flying Dragon' a menor ocorrência de sementes poliembriônicas (Tabela 4).

Os resultados observados em relação ao número de embriões e à taxa de poliembrionia observados por sementes nos híbridos UFLAD-2, UFLAD-3 e UFLAD-4 são superiores aos observados em limão 'Cravo', que apresenta em média e 1,5 embrião por semente e $35,2 \%$ de sementes poliembriônicas (SOARES-FILHO, 2000) e em P. trifoliata com porcentagens de poliembrionia de $31,5 \%$, e números de embriões por semente de 1,4 (RAMOS et al., 2006). Os valores observados podem ser variáveis em função do grau de maturidade do embrião, pois geralmente o número de embriões e a contagem em sementes germinadas em substratos caem, significativamente, em relação à contagem direta em sementes não germinadas (SOARES-FILHO, 2002; ANDRADERODRÍGUEZ).

O número de embriões por semente varia, entre e dentro de variedades, em decorrência das influências do meio ambiente e dos genótipos envolvidos nas hibridações. Em sementes híbridas de Citrus sinensis (L). cv. Natal com P. trifoliata, Ribeiro et al. (1999) encontraram até 20 embriões em sementes de frutos imaturos.

Para as correlações do número de embriões por sementes e o IVG, foram observadas nas sementes em que não foi realizada a remoção do tegumento, correlações negativas para o híbrido UFLAD-2 (-0,7106), o UFLAD-3 $(-0,8823)$ e para o UFLAD-4 $(-0,7594)$, enquanto nas sementes em que feita a remoção do tegumento, apenas o híbrido UFLAD-3 apresentou correlação positiva do número de embriões com o IVG. Não houve correção do número de embriões com a germinação para nenhum dos porta-enxertos avaliados.

Os resultados sugerem não haver competição, entre os vários embriões, que prejudique a germinação das sementes. A correlação negativa observada nos híbridos com maior número de embriões, possivelmente, ocorreu em função do tegumento coriáceo das sementes desses porta-enxertos que representou um impedimento à absorção de água, causando menor expressão do vigor nas sementes com maior número de embriões por sementes, o que não ocorreu nas sementes que tiveram o tegumento removido. 
TABELA 1 - Médias do diâmetro transversal (DT), diâmetro longitudinal (DL) e massa dos frutos (MF), número total de sementes por fruto (NTS) e número de sementes viáveis por fruto, dos portaenxertos de citros.

\begin{tabular}{cccccc}
\hline Porta-Enxerto & DT & DL & PF & NTS & NSV \\
\hline UFLAD-2 & $48,25 \mathrm{~b}$ & $43,75 \mathrm{~b}$ & $57,50 \mathrm{~b}$ & $17 \mathrm{c}$ & $14 \mathrm{c}$ \\
UFLAD-3 & $44,75 \mathrm{c}$ & $40,50 \mathrm{c}$ & $47,25 \mathrm{c}$ & $12 \mathrm{~d}$ & $10 \mathrm{~d}$ \\
UFLAD-4 & $46,75 \mathrm{~b}$ & $42,75 \mathrm{~b}$ & $53,50 \mathrm{~b}$ & $16 \mathrm{c}$ & $13 \mathrm{c}$ \\
Flying Dragon & $43,50 \mathrm{c}$ & $42,00 \mathrm{~b}$ & $45,25 \mathrm{c}$ & $43 \mathrm{~b}$ & $36 \mathrm{a}$ \\
Citrumeleiro 'Swingle' & $65,00 \mathrm{a}$ & $65,25 \mathrm{a}$ & $130,50 \mathrm{a}$ & $58 \mathrm{a}$ & $26 \mathrm{~b}$ \\
\hline CV (\%) & 2,2 & 2,7 & 6,5 & 5,7 & 5,8 \\
\hline
\end{tabular}

*Médias seguidas de letras diferentes na coluna diferem entre si, pelo teste de Scott-Knott, a 5\% de probabilidade de erro.

TABELA 2 - Correlações de Pearson para diâmetro transversal do fruto (DT) e o número total de sementes por fruto (NTS), e número de sementes viáveis (NSV) e massa (M), e o número total de sementes por fruto (NTS) e número de sementes viáveis (NSV) por fruto, dos porta-enxertos de citros.

\begin{tabular}{ccccc}
\hline \multirow{2}{*}{ Porta- Enxerto } & \multicolumn{4}{c}{ Variáveis } \\
\cline { 2 - 5 } & DT x NTS & DT x NSV & M x NTS & Mx \\
\hline USV \\
\hline UFLAD-2 & $-0,8597^{\text {ns }}$ & $-0,9366^{*}$ & $-0,871^{\text {ns }}$ & $-0,9311^{*}$ \\
UFLAD-4 & $0,557^{\text {ns }}$ & $0,2799^{\text {ns }}$ & $0,2813^{\text {ns }}$ & $-0,0598^{\text {ns }}$ \\
'Flying Dragon' & $-0,0206^{\text {ns }}$ & $-0,02^{\text {ns }}$ & $0,0327^{\text {ns }}$ & $0,1839^{\text {ns }}$ \\
Citrumeleiro 'Swingle' & $0,0455^{\text {ns }}$ & $-0,1017^{\text {ns }}$ & $0,1717^{\text {ns }}$ & $0,0857^{\text {ns }}$ \\
\hline
\end{tabular}

${ }^{\text {ns }}$ não significativo; * significativo a $5 \%$, pelo teste $\mathrm{t}$

TABELA 3 - Médias do índice de velocidade de germinação (IVG), porcentagem de germinação e número de embriões germinados por sementes (NES), em sementes com e sem tegumento, dos portaenxertos de citros.

\begin{tabular}{ccccccc}
\hline \multirow{2}{*}{ Porta- Enxerto } & \multicolumn{2}{c}{ IVG* $^{*}$} & \multicolumn{2}{c}{ Germinação (\%) } & \multicolumn{2}{c}{$\mathrm{N}^{\circ}$ de E/S } \\
\cline { 2 - 7 } & $\begin{array}{c}\text { Com } \\
\text { tegumento }\end{array}$ & $\begin{array}{c}\text { Sem } \\
\text { tegumento }\end{array}$ & $\begin{array}{c}\text { Com } \\
\text { tegumento }\end{array}$ & $\begin{array}{c}\text { Sem } \\
\text { Tegumento }\end{array}$ & $\begin{array}{c}\text { Com } \\
\text { tegumento }\end{array}$ & $\begin{array}{c}\text { Sem } \\
\text { tegumento }\end{array}$ \\
\hline UFLAD-2 & $0,09 \mathrm{~B} \mathrm{a}$ & $1,12 \mathrm{~A} \mathrm{a}$ & $25,00 \mathrm{~B} \mathrm{a}$ & $92,50 \mathrm{~A} \mathrm{a}$ & $2,0 \mathrm{~B} \mathrm{a}$ & $2,5 \mathrm{~A} \mathrm{a}$ \\
UFLAD-3 & $0,16 \mathrm{~B} \mathrm{a}$ & $1,25 \mathrm{~A} \mathrm{a}$ & $21,25 \mathrm{~B} \mathrm{a}$ & $97,50 \mathrm{~A} \mathrm{a}$ & $2,1 \mathrm{~B} \mathrm{a}$ & $2,5 \mathrm{~A} \mathrm{a}$ \\
UFLAD-4 & $0,09 \mathrm{~B} \mathrm{a}$ & $1,11 \mathrm{~A} \mathrm{a}$ & $18,75 \mathrm{~B} \mathrm{a}$ & $93,75 \mathrm{~A} \mathrm{a}$ & $1,9 \mathrm{~B} \mathrm{a}$ & $2,7 \mathrm{~A} \mathrm{a}$ \\
'Flying Dragon' & $0,03 \mathrm{~B} \mathrm{~b}$ & $0,46 \mathrm{~A} \mathrm{c}$ & $6,25 \mathrm{~B} \mathrm{~b}$ & $48,75 \mathrm{~A} \mathrm{c}$ & $1,2 \mathrm{~A} \mathrm{~b}$ & $1,0 \mathrm{~A} \mathrm{~b}$ \\
Citrumeleiro 'Swingle' & $0,31 \mathrm{~B} \mathrm{a}$ & $0,92 \mathrm{~A} \mathrm{~b}$ & $18,75 \mathrm{~B} \mathrm{a}$ & $81,25 \mathrm{~A} \mathrm{~b}$ & $1,2 \mathrm{~A} \mathrm{~b}$ & $1,3 \mathrm{~A} \mathrm{~b}$ \\
\hline CV(\%) & & 21,5 & & 11,9 & \multicolumn{2}{c}{13,8} \\
\hline
\end{tabular}

* Médias seguidas de letras diferentes, minúscula na coluna e maiúscula na linha para cada variável, diferem entre si, pelo teste de Scott-Knott, a 5\% de probabilidade de erro. 
TABELA 4 - Porcentagem de poliembrionia em sementes germinadas dos porta-enxertos de citros.

\begin{tabular}{cc}
\hline Porta-Enxerto & Poliembrionia (\%) \\
\hline UFLAD-2 & $81,3 \mathrm{a}$ \\
UFLAD-3 & $81,0 \mathrm{a}$ \\
UFLAD-4 & $79,1 \mathrm{a}$ \\
'Flying Dragon' & $13,4 \mathrm{~b}$ \\
Citrumeleiro 'Swingle' & $21,1 \mathrm{~b}$ \\
\hline CV (\%) & 25,3 \\
\hline
\end{tabular}

*Médias seguidas de letras diferentes na coluna diferem entre si, pelo teste de Scott-Knott, a 5\% de probabilidade de erro.

TABELA 5 - Correlações de Pearson para número de embriões (NE) e o índice de velocidade de emergência (IVG), e número de embriões com a germinação (G), em sementes com e sem tegumento, dos porta-enxertos de citros.

\begin{tabular}{ccccc}
\hline & \multicolumn{4}{c}{ Variáveis } \\
\cline { 2 - 5 } Porta- Enxerto & NE x IVG & NE x IVG & NE x G & NE x G \\
\cline { 2 - 5 } & $\begin{array}{c}\text { Com } \\
\text { tegumento }\end{array}$ & $\begin{array}{c}\text { Sem } \\
\text { tegumento }\end{array}$ & $\begin{array}{c}\text { Com } \\
\text { tegumento }\end{array}$ & $\begin{array}{c}\text { Sem } \\
\text { tegumento }\end{array}$ \\
\hline UFLAD-2 & $-0,7106^{*}$ & $0,6213^{\text {ns }}$ & $0,2236^{\text {ns }}$ & $0,3487^{\text {ns }}$ \\
UFLAD-3 & $-0,8823^{*}$ & $0,9672^{*}$ & $-0,8786^{\text {ns }}$ & $0,7071^{\text {ns }}$ \\
UFLAD-4 & $-0,7594^{*}$ & $0,7625^{\text {ns }}$ & $0,0228^{\text {ns }}$ & $-0,0580^{\text {ns }}$ \\
'Flying Dragon' & $0,7843^{\text {ns }}$ & $-0,3616^{\text {ns }}$ & $0,5401^{\text {ns }}$ & $-0,7493^{\text {ns }}$ \\
Citrumeleiro 'Swingle' & $0,6333^{\text {ns }}$ & $0,6384^{\text {ns }}$ & $0,1424^{\text {ns }}$ & $-0,1741^{\text {ns }}$ \\
\hline
\end{tabular}

${ }^{\mathrm{ns}}$ não significativo; * significativo a $5 \%$, pelo teste $\mathrm{t}$

\section{CONCLUSÕES}

1-O tamanho do fruto não influencia no número de sementes.

2-A remoção do tegumento acelera o tempo de germinação das sementes em todos os porta-enxertos e proporciona maior percentual de germinação.

3-A poliembrionia não afeta o processo de germinação das sementes.

4-Os porta-enxertos UFLAD-2, UFLAD-3, UFLAD-4 e Citrumeleiro 'Swingle' apresentam potencial para serem utilizados na produção de porta-enxertos.

\section{REFERÊNCIAS}

ANDRADE-RODRÍGUEZ, M.; VILLEGASMONTER, A.; CARRILLO-CASTAÑEDA , G.; GARCÍA-VELÁZQUEZ, A. Polyembryony and identification of Volkamerian lemon zygotic and nucellar seedlings using RAPD. Pesquisa Agropecuária Brasileira, Brasília, v.39, n.6, p.551-559, 2004.
OLIVEIRA, R. P.; SCIVITTARO, W. B. Formação do porta-enxerto Trifoliata: época de semeadura e tegumento na emergência de plântulas. Ciência Rural, Santa Maria, v.37, n.1, p.281-283, 2007.

OLIVEIRA, R.P.; SCIVITTARO, W.B.; BORGES, R. de SÁ; NAKASU, B.H. Mudas de citros. Pelotas: Embrapa Clima Temperado, 2001.32p. (Sistemas de Produção, 1).

PASSOS, O.S.; PEIXOUTO, L.S.; SANTOS, L.C.; CALDAS, R.C.; SOARES FILHO, W.S. Caracterização de híbridos de Poncirus trifoliata e de outros porta-enxertos de citros no Estado da Bahia. Revista Brasileira Fruticultura, Jaboticabal, v.28, n.3, p.410-413, 2006.

RAMOS, J.D.; ARAÚJO NETO, S.E.; CASTRO, N.E.A.; MARTINS, P.C.C.; CORREIA, M.G. Poliembrionia e caracterização de frutos de citrumelo swingle e de Poncirus trifoliata. Ciência e Agrotecnologia, Lavras, v.30, n.1, p.88-91, 2006 
RAMOS, J.D.; PASQUAL, M.; RIBEIRO, V.G.; ANTUNES, L. E. C. Obtenção de porta-enxertos intergenéricos em citros. Pesquisa Agropecuária Brasileira, Brasília, v.32, n.10, p.1047-1051, 1997.

RIBEIRO, V. G.; PASQUAL, M.; RAMOS, J. D.; BEARZOTI, E.; D ANGELO NETO, S. Estádios e desenvolvimento embrionário e localização do embrião zigótico em sementes de citros. Pesquisa Agropecuária Brasileira, Brasília, v.34, n.8, p.1327$1333,1999$.

ROUSE, R.E. Optimum temperatures for germinating citrus seeds. Proceedings of the Interamerican Society for Tropical Horticulture, Campeche, v.41, p.136-139, 1997.

SCHÄFER, G.; SOUZA, P. V. D.; DAUDT, R. H. S.; DORNELLES, A. L. C. Substratos na emergência de plântulas e expressão da poliembrionia em portaenxertos de citros. Ciência Rural, Santa Maria, v.35, n.2, p.471-474, 2005.
SOARES FILHO, W. dos S.; MEDRADO, A. C. de M.; CUNHA, M. A. P. da; CUNHA SOBRINHO, A. P. da; PASSOS, O. S. Frequência de híbridos em cruzamentos controlados de citros: cultivo de sementes versus cultivo in vitro de embriões. Pesquisa Agropecuária Brasileira, Brasília, v.37, n.7, p.981-988, 2002.

SOARES FILHO, W. dos S.; MOREIRA, C. dos S.; CUNHA, M. A. P. da; CUNHA SOBRINHO, A. P. da; PASSOS, O. S. Poliembrionia e frequência de híbridos em Citrus spp.. Pesquisa Agropecuária Brasileira, Brasília, v. 35, n. 4, p. 857-864, 2000.

SOUSA, H. U.; RAMOS, J. D.; PASQUAL, M.; FERREIRA, E. A. Efeito do ácido giberélico sobre a germinação de sementes de porta-enxertos cítricos. Revista Brasileira de Fruticultura, Jaboticabal, v.24, n.2, p.496-499, 2002. 